Article

\title{
Climate Resilient Low-Income Tropical Housing
}

\author{
Arman Hashemi ${ }^{1,2}$ \\ 1 Centre for Sustainable Development, Department of Engineering, University of Cambridge, \\ Cambridge CB2 1PZ, UK; a.hashemi@eng.cam.ac.uk \\ 2 School of Environment and Technology, University of Brighton, Brighton BN2 4GJ, UK; \\ a.hashemi@brighton.ac.uk; Tel.: +44-1273-642-272
}

Academic Editors: Vincenzo Dovì and Antonella Battaglini

Received: 25 April 2016; Accepted: 9 June 2016; Published: 17 June 2016

\begin{abstract}
Located in East Africa, Uganda is one of the most economically deprived countries that is likely to be dramatically affected by climate change. Over $50 \%$ of Ugandan families live in single-roomed overcrowded properties and over $60 \%$ of the country's urban population live in slums. Moreover, the gradual shift towards relatively modern and low thermal resistance building materials, in addition to imminent thermal discomfort due to global warming, may considerably affect the health and wellbeing of low-income people, the majority of whom live in low quality homes with very little or no access to basic amenities. This paper evaluates the effects of various construction methods as well as refurbishment strategies on thermal comfort in low-income houses in Uganda. It is aimed at helping low-income populations adapt to climate changes by developing simple, effective and affordable refurbishment strategies that could easily be applied to existing buildings. Dynamic thermal simulations are conducted in EnergyPlus. The adaptive model defined in BS EN 15251 and CIBSE TM52 is used to evaluate the risk and extent of thermal discomfort. Roofing methods/materials are found to be the key factor in reducing/increasing the risk of overheating. According to the results, roof insulation, painting the roof with low solar absorptance materials and inclusion of false ceilings are, respectively, the most effective and practical refurbishment strategies in terms of improving thermal comfort in low-income houses in Uganda. All refurbishment strategies helped to pass Criterion 3 of CIBSE TM52, as an indicator of "future climate scenarios", making low-income houses/populations more climate resilient.
\end{abstract}

Keywords: thermal comfort; climate change; resilience; refurbishment; low-income; tropical; housing; Uganda; Africa

\section{Introduction}

Located in East Africa, Uganda occupies an area of 241,038 square kilometres [1] and has an estimated population of 39 million [2]. In 2014, Uganda was ranked 163 out of 188 countries on the Human Development Index (HDI) that "assesses human wellbeing from a broad perspective", including the "ability to achieve a decent standard of living, measured by gross national income per capita" [3]. Around 38\% of Uganda's population live below the international income poverty line with a daily income of $\$ 1.25$ or less [3]. Moreover, around $60 \%$ of the country's urban population live in slums [4,5]; over $50 \%$ live in single-roomed properties [6] and only $18 \%$ have access to electricity. The situation is more critical in rural areas as only $8 \%$ of rural households have access to electricity [3] compared to $55 \%$ in urban areas [7]. The rural population accounts for around $85 \%$ of the total population in Uganda [8].

The climatic conditions in Uganda vary from hot arid climate in the north to tropical equatorial climate in the south. The local climatic conditions are greatly affected by the altitude and rainfall [9]. Overall, Uganda has a tropical climate moderated by an average altitude of $1100 \mathrm{~m}$ above sea level [10]. 
The mean annual rainfall in different parts of the country varies between 750 and $2000 \mathrm{~mm}[1,11]$, and the mean annual temperature varies between $16^{\circ} \mathrm{C}$ and $30^{\circ} \mathrm{C}$ [11] with the hottest periods between December and February [10].

Currently, the embodied energy of construction methods and materials is the key factor in evaluating the environmental impacts of low-income houses in Uganda [12,13]; however, global warming is expected to increase the average air temperature by $3-4{ }^{\circ} \mathrm{C}$ during the next 70 years [9], which may transform operational energy into a major issue in the near future. Moreover, the gradual replacement of sustainable materials, such as adobe and thatched roofs, with environmentally damaging low thermal resistance materials, such as concrete and iron sheet roofs, may deteriorate thermal comfort conditions leading to an increased use of air conditioning, more energy demand and increased $\mathrm{CO}_{2}$ emissions of the housing sector, which, in turn, contribute to even more climate changes and their associated problems.

Defective design, poor workmanship and low quality construction methods/materials in addition to overcrowding and imminent thermal discomfort due to global warming may considerably affect the health and wellbeing of low-income people, the majority of whom live in substandard houses with limited or no access to basic amenities. Indeed, "climate-proofing" of existing infrastructure is the major strategy of many developing countries in response to the increasing risks posed by climate changes. However, due to limited resources, climate adaptation in the poorest countries is left to individuals as a matter of "self-help" [14]. This situation puts low-income populations in an even more vulnerable position, as they generally have less access to resources to adapt to climate changes.

To this end, this paper intends to evaluate the effects of various construction methods and materials on the risk and extent of thermal discomfort in low-income naturally ventilated houses in Uganda (Figure 1). The ultimate aim is to help low-income populations adapt to climate changes, making them more climate resilient by developing simple, effective and affordable refurbishment strategies to improve thermal comfort and reduce the risk of overheating in their homes. This document is an extended version of a conference paper on thermal comfort conditions in Uganda [15].

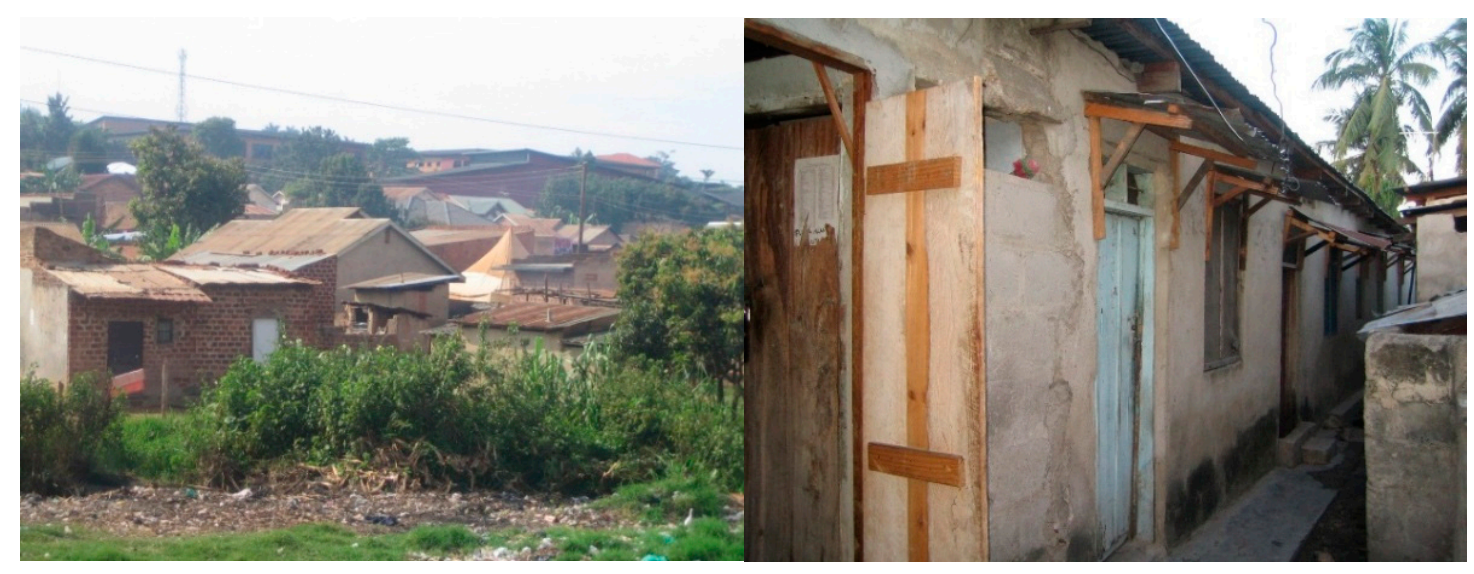

Figure 1. Low-income housing and slums.

\section{Housing Conditions and Construction Methods}

Detached houses (58\%) followed by huts (21.5\%) and tenements (18.4\%) are the most common housing types in Uganda [16]. Overcrowding is a major issue in Uganda, particularly in the low-income housing sector. The average number of people sleeping in one room in over 50\% of Ugandan households is four or more [15]. The low construction quality along with limited access to good quality materials are some of the other major problems of the Ugandan housing industry. Table 1 summarises the most common construction methods and materials used in housing projects in Uganda. 
Table 1. Construction methods and materials in Uganda (\%) [16].

\begin{tabular}{ccccc}
\hline Building Component & Material & Rural & Urban & Uganda \\
\hline \multirow{4}{*}{ Roof } & Iron sheet & 56.7 & 84.1 & 61.8 \\
& Thatch & 42.6 & 12 & 36.9 \\
& Other & 0.7 & 4 & 1.3 \\
& Total * & 100 & 100 & 100 \\
\hline \multirow{4}{*}{ Wall } & Brick & 50.9 & 83.9 & 57.1 \\
& Mud and Poles & 45.7 & 12.4 & 39.4 \\
& Other & 3.4 & 3.8 & 3.5 \\
& Total * & 100 & 100 & 100 \\
\hline \multirow{4}{*}{ Floor } & Earth/Soil & 82.1 & 25.2 & 71.4 \\
& Cement/Concrete & 16.9 & 70.8 & 27 \\
& Other & 1 & 4 & 1.5 \\
& Total * & 100 & 100 & 100 \\
\hline
\end{tabular}

* There may be $0.1 \%$ discrepancies.

Around $62 \%$ of homes in Uganda are covered with iron sheets (Figure 2) and 37\% have thatched roofs. Brick walling is the most common walling material (57\%) followed by mud and poles $(39 \%)$. With a share of over $70 \%$, cement/concert flooring is the most common flooring method/material in urban areas of the country $[6,16]$. The available data indicate that there is a growing shift away from traditional materials (such as adobe and thatch) towards relatively modern methods and materials (such as bricks and iron sheets) $[12,13]$.

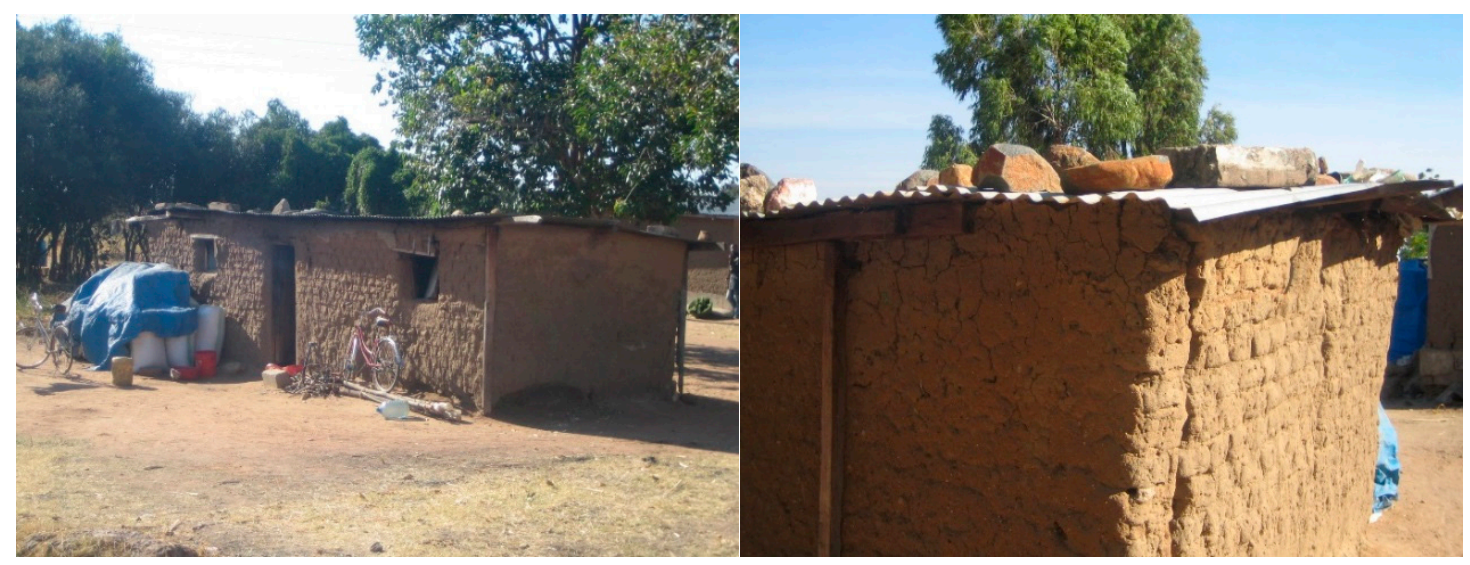

Figure 2. A low-income house with clay walls and an iron sheet roof.

\section{Research Methodology}

Dynamic thermal simulations are conducted in EnergyPlus to evaluate the effects of various construction materials and refurbishment strategies on thermal comfort in low-income houses. The study is divided into two sections as follows:

A Section A: Prevailing roofing systems (i.e., iron sheet and thatched) are simulated in combination with the common walling materials (i.e., adobe, burned/fired bricks, stabilised soil blocks, solid concrete blocks and hollow concrete blocks) for a fixed wall thickness of $200 \mathrm{~mm}$. Ten combination scenarios are therefore simulated in total (five walling materials and two roofing systems). The most critical factors on thermal comfort are identified in the first section as the basis for refurbishment strategies investigated in Section B of this study.

B Section B: Refurbishment strategies are investigated for the most common construction methods in low-income houses in Uganda. The aim is to develop relatively simple and effective refurbishment strategies for low-income people to improve the conditions. The following refurbishment 
strategies are considered for improving thermal performance of the most critical building elements identified in Section A of the study:

- Inclusion of false ceiling

- Insulated ceiling (50 mm insulation): "cold roof"

- Insulated roof (50 mm insulation): "warm roof"

- $\quad$ Painted roof: white painted roof with low solar absorptance

- Double skin roofing: an additional layer of iron sheet spaced $100 \mathrm{~mm}$ above the existing roof

The tested scenarios in sections A and B are summarised in Table 2. The materials' properties were defined based on the available information in CIBSE Guide A [17,18] (Table 3).

Table 2. Tested scenarios for prevailing methods of construction and refurbishment strategies.

\begin{tabular}{ll}
\hline \multicolumn{1}{c}{ Current Conditions } & \multicolumn{1}{c}{ Tested Scenarios } \\
\hline Adobe \& Iron Sheet/Thatched Roof & Insulated iron sheet roof (warm roof) \\
Brick \& Iron Sheet/Thatched Roof & Painted iron sheet roof \\
Hollow Concrete Blocks \& Iron Sheet/Thatched Roof & Iron sheet roof with ceiling \\
Solid Concrete Blocks \& Iron Sheet/Thatched Roof & Iron sheet roof with insulated ceiling (cold roof) \\
Stabilised Soil Blocks \& Iron Sheet/Thatched Roof & Double skin iron sheet roof \\
\hline
\end{tabular}

Table 3. Material properties used in the simulations.

\begin{tabular}{cccc}
\hline Material & $\begin{array}{c}\text { Thermal Conductivity } \\
\mathbf{( W / m} \cdot \mathbf{K})\end{array}$ & $\begin{array}{c}\text { Thickness } \\
(\mathbf{m})\end{array}$ & $\begin{array}{c}\text { Density } \\
\left.\mathbf{( K g} / \mathbf{m}^{3}\right)\end{array}$ \\
\hline Adobe & 0.60 & 0.200 & 1450 \\
Brick & 1.00 & 0.200 & 1900 \\
Hollow Concrete Block & 0.86 & 0.200 & 875 \\
Solid Concrete Block & 1.31 & 0.200 & 2240 \\
Stabilised Soil Block & 1.10 & 0.200 & 1950 \\
Iron sheet roof (0.7 solar absorptance value) & 37.00 & $0.003^{*}$ & 7800 \\
White iron sheet roof (0.2 solar absorptance value) & 37.00 & $0.003^{*}$ & 7800 \\
Thatched roof & 0.07 & 0.150 & 240 \\
Concrete floor & 1.31 & 0.100 & 2240 \\
Insulation & 0.04 & 0.050 & 240 \\
Plasterboard & 0.20 & 0.012 & 850 \\
Glass & 0.90 & 0.006 & - \\
Window frame & 5.00 & 0.050 & - \\
\hline
\end{tabular}

* Limiting thickness of materials according to EnergyPlus.

The initial simulations on the effects of flooring on thermal comfort revealed that refurbishment strategies would either deteriorate or very marginally improve thermal comfort conditions. Flooring refurbishment strategies were therefore excluded from this study.

A $3 \mathrm{~m} \times 3 \mathrm{~m} \times 3 \mathrm{~m}$ single-roomed property with four occupants was modelled as the representative of low-income housing in urban areas of Uganda, according to the statistical information described above. A $2 \mathrm{~m} \times 1 \mathrm{~m}$ door and a $1 \mathrm{~m} \times 1 \mathrm{~m}$ single glazed window with effective opening areas of $80 \%$ were also considered. For the refurbishment scenarios, where a ceiling was considered, the height of the ceiling was specified as $2.5 \mathrm{~m}$ above the finished floor level. The areas below and above the ceiling were modelled as separate zones to increase the accuracy of the simulations. A similar strategy (2 Zones) was also considered for the double-skin roofing, explained above.

The occupancy pattern was defined as fully occupied (four occupants) from 6 p.m. to 8 a.m. and one occupant from 8 a.m. to 6 p.m. An internal heat gain of $100 \mathrm{~W}$ and $70 \mathrm{~W}$ per person was assumed for seated and sleeping occupants, respectively. The occupants' behaviours in terms of opening and 
closing the windows and doors were also defined as: windows open 6:30 a.m.-6:30 p.m.; doors open 7 a.m.-8 p.m. [19]. Considering there are not any available weather data for dynamic simulations in Uganda, Kisumu in Kenya was used as the closest city to Kampala. Similar to Kampala, Kisumu is located on the shore of Lake Victoria and its altitude is almost the same as Kampala.

Adaptive model Category II (normal expectation for new buildings and renovations), defined in BS EN 15251 [20] along with the flowing overheating criteria, defined in CIBSE TM52 [21], are used to evaluate the risk of thermal discomfort (Table 4).

Table 4. Overheating assessment criteria.

\begin{tabular}{|c|c|c|}
\hline & Assessment Criteria * & Acceptable Deviation \\
\hline Criterion 1 & $\begin{array}{c}\text { Percentage of occupied hours during which } \Delta \mathrm{T} \\
\left(\Delta \mathrm{T}=\mathrm{T}_{\mathrm{op}}-\mathrm{T}_{\max } \text { rounded to the nearest whole degree }\right) \text { is } \\
\text { greater than or equal to } 1^{\circ} \mathrm{C}\end{array}$ & Up to $3 \%$ of occupied hours \\
\hline Criterion 2 & $\begin{array}{l}\text { “Daily weighted exceedance" }\left(\mathrm{W}_{\mathrm{e}}\right) \text { in any one day }>6{ }^{\circ} \mathrm{C} \cdot \mathrm{h} \\
\text { (degree hours) }\end{array}$ & 0 day \\
\hline Criterion 3 & Maximum temperature level $\left(\mathrm{T}_{\mathrm{upp}}\right) \Delta \mathrm{T}>4^{\circ} \mathrm{C}$ & $0 \mathrm{~h}$ \\
\hline
\end{tabular}

\section{Results of Simulations}

Simulations are divided into two sections of A and B. The first section evaluates the current conditions in terms of thermal comfort in low-income houses built with different construction methods/materials. The second section assesses the effects of refurbishment strategies on thermal comfort conditions.

\subsection{Section A: Thermal Comfort Conditions for Prevailing Methods of Construction}

\subsubsection{Adobe Walls with Iron Sheet/Thatched Roof}

Adobe walls with an iron sheet roof failed all three thermal comfort criteria. According to the results, for Criterion $1, \Delta \mathrm{T}$ was over $1{ }^{\circ} \mathrm{C}$ for over $8 \%$ of occupied periods, which is considerably higher than the 3\% acceptable level. The building also failed Criterion 2 as $W_{\mathrm{e}}$ (the daily weighted exceedance) exceeded the limit of six degree-hours for 65 days, which is around 18\% of occupied days. The results also revealed that $\Delta \mathrm{T}$ exceeded the "upper limit temperature" $\left(\mathrm{T}_{\text {upp }}\right)$ for six hours. The situation improved significantly for adobe walls with a thatched roof. The building passed the first and second criteria, but it marginally failed the second Criterion by three days. Overall, the building was considerably more comfortable when the iron sheet roof was replaced with the thatched roof.

\subsubsection{Brick Walls with Iron Sheet/Thatched Roof}

Brick walls had similar performances to adobe walls; however, compared to adobe walls, brick walls performed slightly better with an iron sheet roof and slightly worse with a thatched roof. Similar to the above scenario, brick walls with iron sheet roof failed all three thermal comfort criteria. According to the results, the operative temperature in the building was in nearly $8 \%$ of occupied periods above the acceptable levels. The building also failed Criterion 2, as $W_{\mathrm{e}}$ was above the limit for 56 days. There were also two incidents during which $\Delta \mathrm{T}$ exceeded the upper limit temperature. The conditions improved for brick walls with thatched roof. Although the building failed Criterion 2 by five days, it passed Criterion 1 and Criterion 3 meaning that the buildings were overall thermally comfortable.

\subsubsection{Hollow Concrete Block Walls with Iron Sheet/Thatched Roof}

Hollow concrete blocks had an extremely poor performance despite their lower thermal conductivity $(0.86 \mathrm{~W} / \mathrm{m} \cdot \mathrm{K})$ compared to bricks $(1 \mathrm{~W} / \mathrm{m} \cdot \mathrm{K})$. Indeed, hollow concrete block walls 
failed the requirements regardless of roofing materials. The risk of overheating and thermal discomfort was, however, considerably higher for the iron sheet roof. According to the results, for the iron sheet roof, the building was thermally uncomfortable for $13.7 \%$ of occupied periods. Moreover, $\mathrm{W}_{\mathrm{e}}$ was above the acceptable limit for 148 days ( $41 \%$ of the entire year) with the maximum value of $35^{\circ} \mathrm{C} \cdot \mathrm{h}$ (degree-hours) on the 24th of January. There were 39 incidents during which $\Delta \mathrm{T}$ exceeded the upper limit temperature $\left(\mathrm{T}_{\mathrm{upp}}\right)$, which means that the building also failed Criterion 3 . Replacing iron sheets with thatch helped to pass Criterion 3, although the building still failed Criterion 1 and Criterion 2.

\subsubsection{Solid Concrete Block Walls with Iron Sheet/Thatched Roof}

Solid concrete block walls performed slightly better than brick and adobe walls with an iron sheet roof and slightly worse than adobe walls with a thatched roof. For the iron sheet roof, Criterion 1 was not met as $\Delta \mathrm{T}$ exceeded $1{ }^{\circ} \mathrm{C}$ for around $7 \%$ of occupied periods. $\mathrm{W}_{\mathrm{e}}$ also was over the acceptable limit of six degree hours for 45 days or $12 \%$ of occupied days. As for Criterion $3, \Delta \mathrm{T}$ exceeded the $4{ }^{\circ} \mathrm{C}$ limit in two hours/incidents. Thatched roof construction improved thermal comfort conditions as the building passed Criteria 1 and 3, although it still failed Criterion 2 by five days.

\subsubsection{Stabilised Soil Block Walls with Iron Sheet/Thatched Roof}

Stabilised soil blocks had a comparable performance to all other walls except hollow concrete block walls. Similar to all other walling methods/materials, covering the roof with iron sheets deteriorated the conditions. According to the results, the building was thermally uncomfortable for $7.5 \%$ of occupied periods and therefore failed Criterion 1 . Stabilised soil block walls with iron sheets also failed Criterion 2 and Criterion 3 as $\mathrm{W}_{\mathrm{e}}$ exceeded the acceptable limit for 49 days and $\Delta \mathrm{T}$ was over the $4{ }^{\circ} \mathrm{C}$ limit in two incidents. For the thatched roof construction, Criteria 1, 2 and 3 were reduced to $0.8 \%$, five days and 0 incidents, respectively. Therefore, the building passed thermal comfort criteria with a thatched roof but failed the requirements with an iron sheet roof.

\subsubsection{Section A: Summary of the Findings}

Figure 3 compares the performance of the tested scenarios over a hot summer week during the 24th to 31st of January. According to the results, the most critical factor affecting occupants' thermal comfort in the studied scenarios is the roof construction method/material. Apart from hollow concrete blocks, all walling methods with thatched roofs passed the thermal comfort requirements (passed at least two criteria out of three). For iron sheet roofing, buildings failed all three thermal comfort criteria regardless of walling method/material.

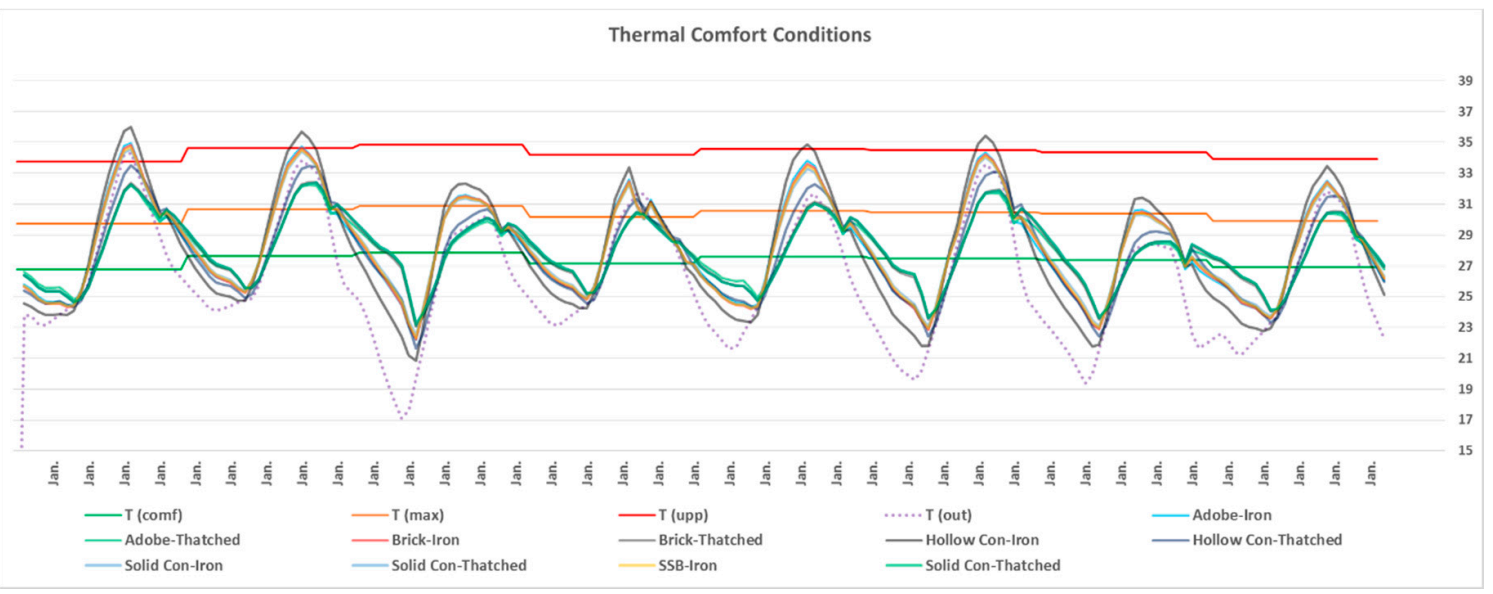

Figure 3. Thermal comfort conditions for tested construction methods during a hot summer week in January. 
Overall, the results of Section A reveal that the best conditions in terms of thermal comfort were achieved for adobe walls with a thatched roof and the worst conditions occurred for hollow concrete walls with an iron sheet roof, which dramatically failed all TM52 thermal comfort criteria. A possible explanation for the poor performance of hollow concrete blocks is the lower thermal mass of the blocks compared to other tested materials. High thermal mass acts as a buffer reducing sharp temperature fluctuations in buildings. Unlike the other walling materials, the low thermal mass of hollow concrete blocks resulted in relatively sharp indoor temperature swings and thermal discomfort. Indeed, the operative temperature for hollow concrete walls significantly exceeded the maximum comfortable temperature $\left(\mathrm{T}_{\max }\right)$ during the day (Figure 3). Moreover, during hot summer days, the operative temperature was occasionally above the absolute maximum temperature level $\left(\mathrm{T}_{\text {upp }}\right.$ ) meaning extreme thermal discomfort (Figures 3 and 4 ). Figure 4 compares the performance of the best and worst performing methods over the entire year.

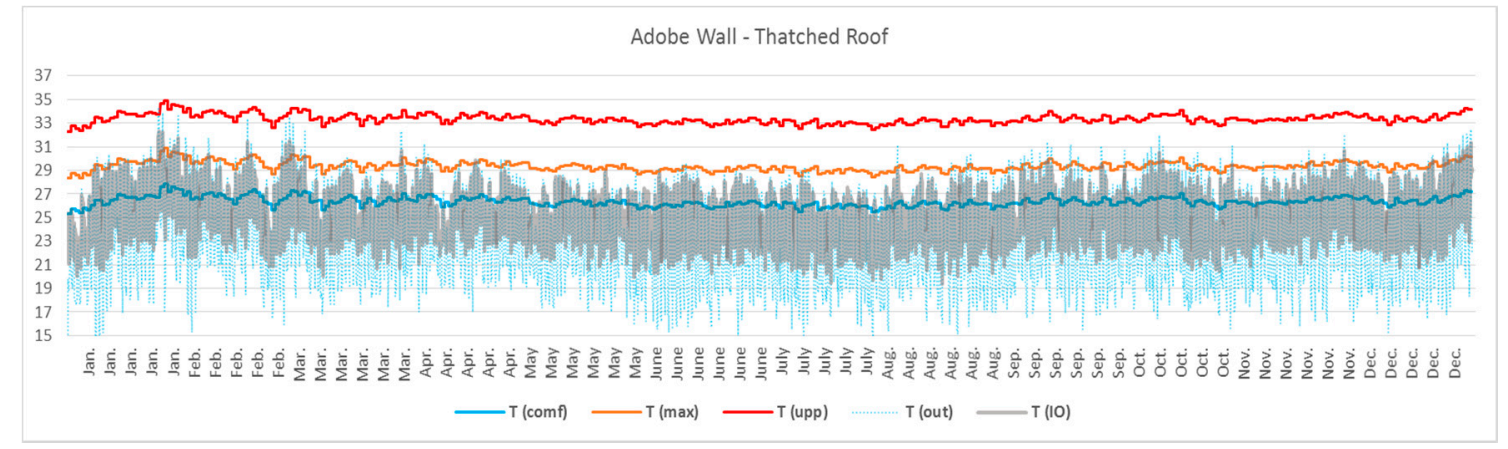

(a)

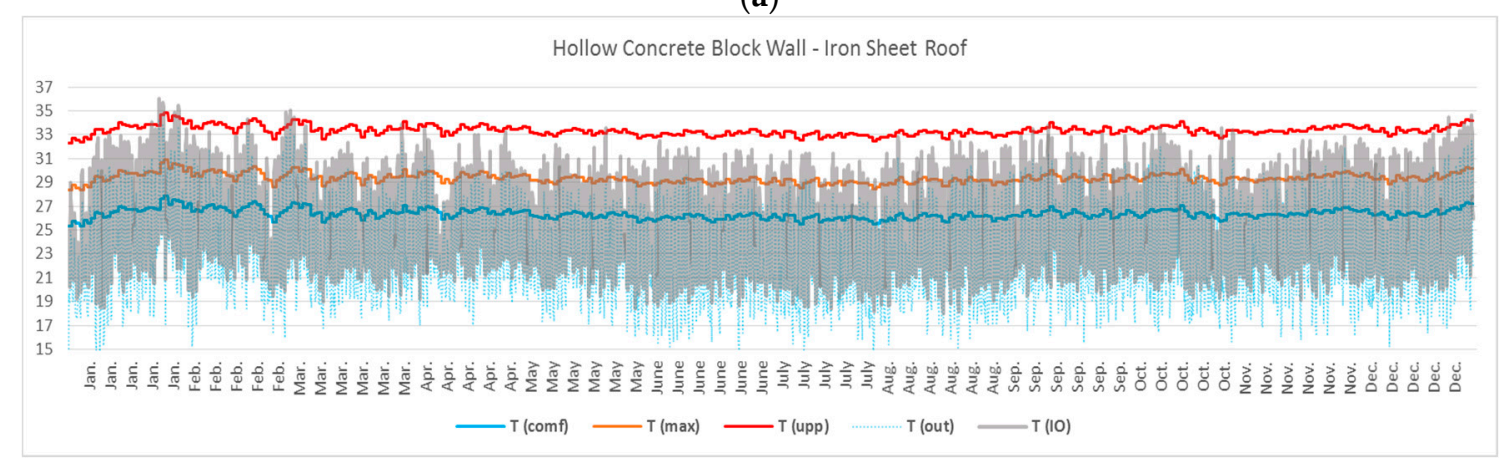

(b)

Figure 4. The best (a) Adobe Walls and Thatched Roof; and the worst (b) Hollow Concrete Walls and Iron Sheet Roof conditions in terms of thermal comfort.

\subsection{Section B: Refurbishment Strategies}

The aim of Section B is to identify simple and effective refurbishment strategies to improve thermal comfort conditions in the existing naturally ventilated low-income houses in Kampala. Although, according to the results of Section A, hollow concrete block walls with an iron sheet roof had the worst performance, all other walling materials combined with iron sheet roofing resulted in critical conditions and failed to provide acceptable thermal comfort conditions. Considering the share of brick walling (57\%) and iron sheet roofs (62\%) in Uganda [16], arguably the majority of low-income houses in Uganda are made from brick walls and iron sheet roofs (Figure 5). The refurbishment strategies are therefore investigated for brick walls and iron sheet roofs as the most common method of construction in Uganda. 


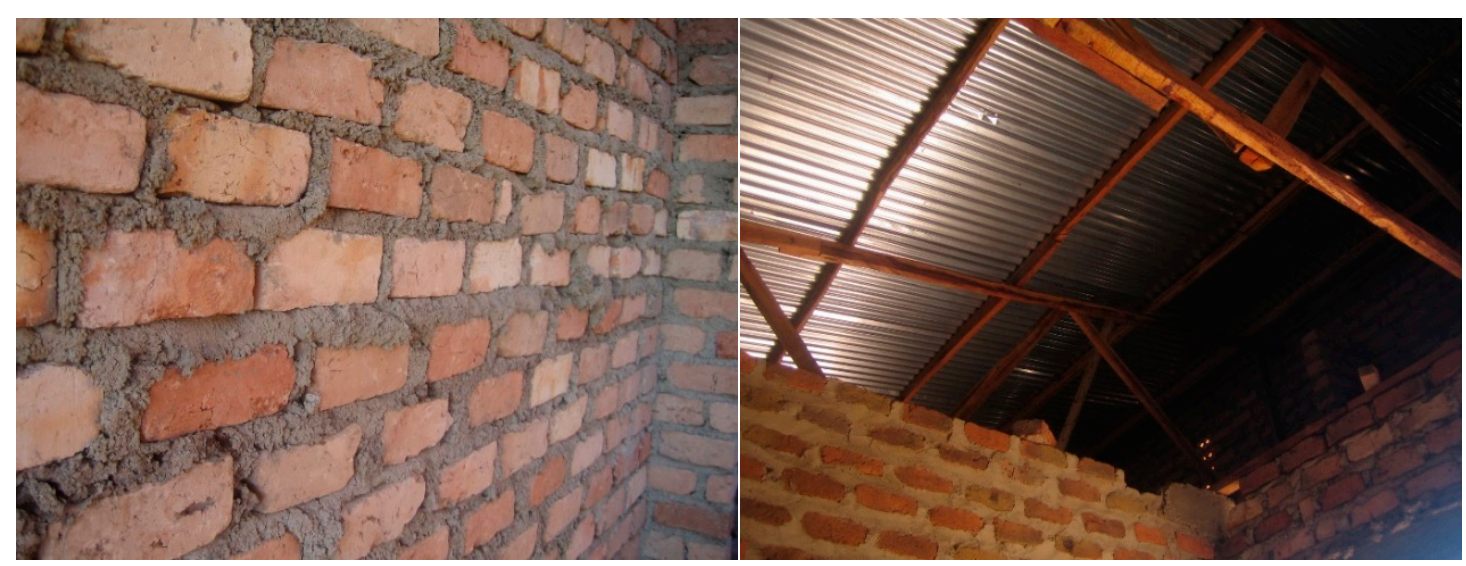

Figure 5. Brick walling and iron sheet roofing is the prevailing construction method in Uganda.

It should be noted that, to avoid complexity and potential high costs, only simple refurbishment strategies are being investigated; however, obviously a combination of the following strategies could further enhance the thermal comfort conditions. The results of simulations for the following refurbishment strategies are explained in this section:

- Inclusion of plasterboard ceiling (12 mm)

- Insulated ceiling (50 mm insulation; $12 \mathrm{~mm}$ plasterboard): cold roof

- Insulated roof (50 mm insulation): warm roof

- $\quad$ Painted roof: white painted roof with low solar absorptance

- Double skin roofing: an additional layer of iron sheet spaced $100 \mathrm{~mm}$ above the existing roof

Figure 6 shows the thermal performance of brick walls with iron sheet roofing (explained in Section A) as the base case for comparison in Section B.

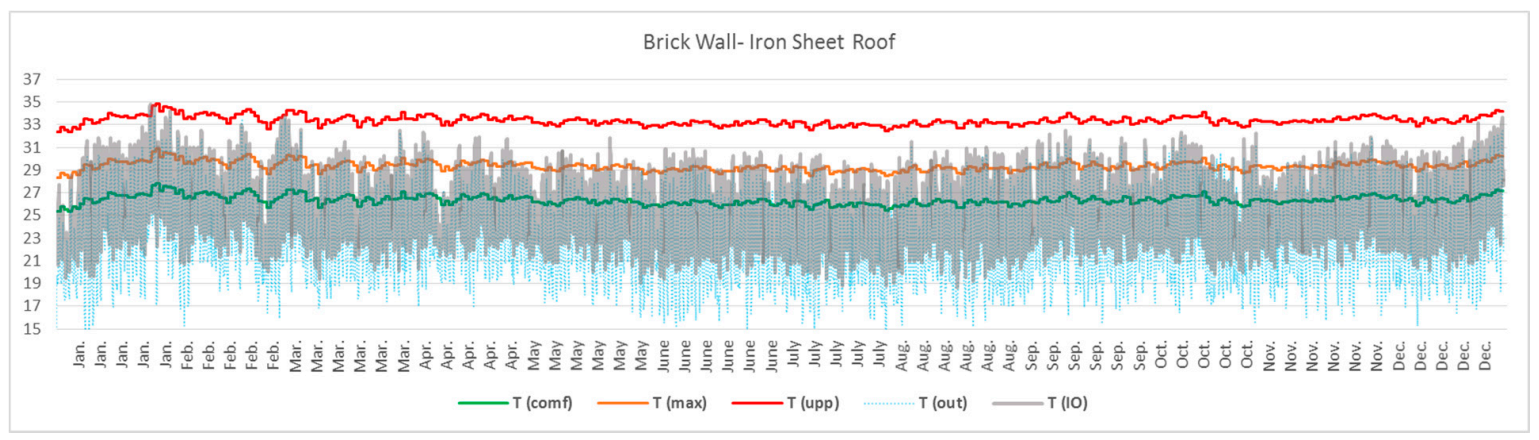

Figure 6. Thermal comfort condition for the base case (Brick Walls \& Iron Sheet Roof).

\subsubsection{Brick Walls with Iron Sheet Roof and Plasterboard Ceiling}

Inclusion of false ceiling significantly improved the conditions and helped to pass two out of the three thermal comfort criteria. The indoor operative temperature was for $2.57 \%$ of occupied periods by $1 \mathrm{~K}$ or more above the limiting maximum acceptable temperature, meaning that it passed the first Criterion. The building, however, failed Criterion 2, as $W_{\mathrm{e}}$ exceeded the limiting six degree hours for ten days ( $2.7 \%$ of occupied periods). As for Criterion 3 ( $\Delta \mathrm{T}$ exceeding $4 \mathrm{~K}$ ), there were zero hours during which $\Delta \mathrm{T}$ exceeded the "upper limit temperature" $\left(\mathrm{T}_{\mathrm{upp}}\right)$. Overall, the building proved to be more thermally comfortable compared to the base case (brick walls and iron sheet roof). Figure 7 shows thermal comfort conditions during the entire year for brick walls with iron sheet roof and plasterboard ceiling. 


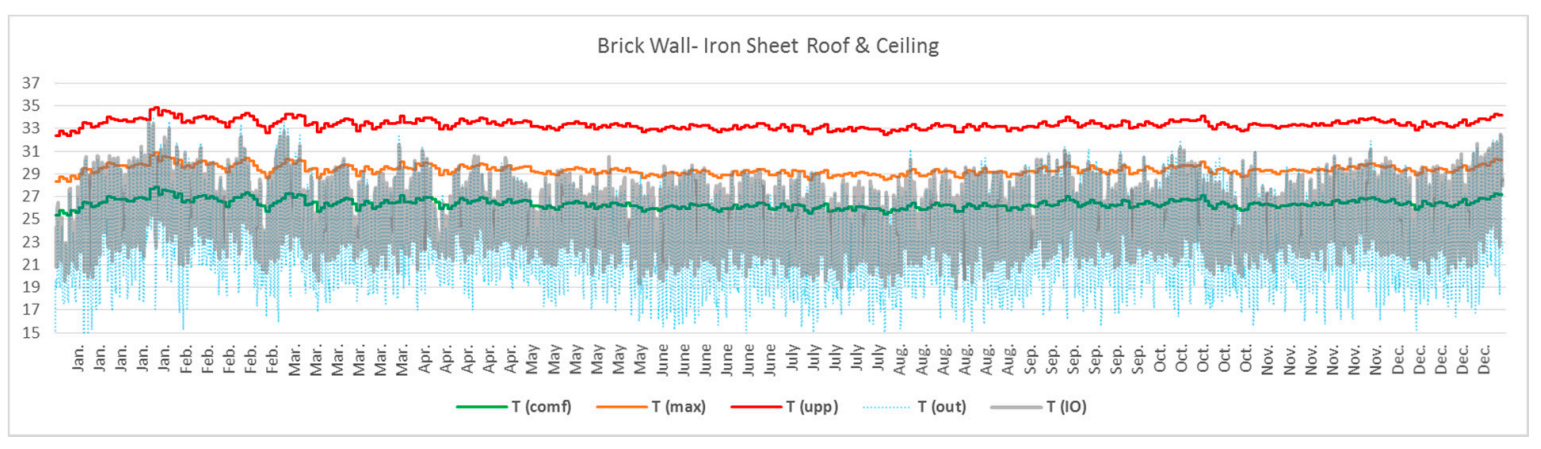

Figure 7. Thermal comfort condition for brick walls with iron sheet roof and plasterboard ceiling.

\subsubsection{Brick Walls with Iron Sheet Roof and Insulated Ceiling}

As expected, including $50 \mathrm{~mm}$ of insulation above the ceiling further improved the conditions, although the improvement was marginal. The results of simulations revealed that brick walls with iron sheet roof and insulated ceiling passed Criterion 1 and 3, but, similar to the above, failed Criterion 2 with seven days exceeding the acceptable conditions. The indoor operative temperature was for $1.02 \%$ of occupied periods by $1 \mathrm{~K}$ or more above the limiting maximum acceptable temperature; however, $\Delta \mathrm{T}$ never exceeded the maximum temperature by more than $4 \mathrm{~K}$. Figure 8 shows the results of simulations for brick walls with iron sheet roof and insulated ceiling construction.

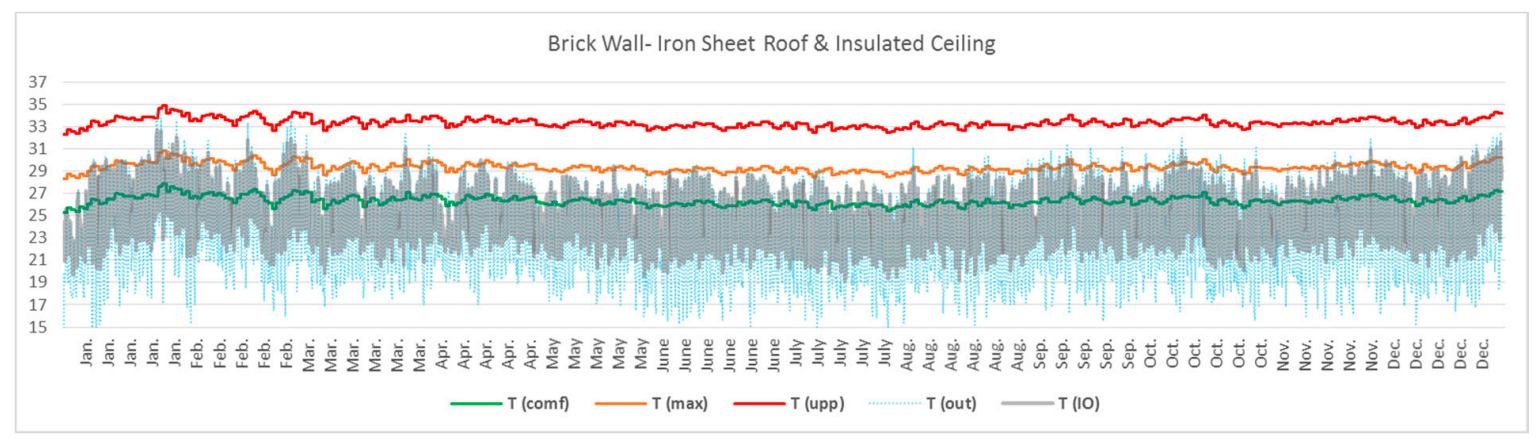

Figure 8. Thermal comfort condition for brick walls with iron sheet roof and insulated ceiling.

\subsubsection{Brick Walls with Insulated Iron Sheet Roof}

Roof insulation also improved the conditions. Both insulated ceiling and insulated roof achieved almost the same results. According to the results, for insulated iron sheet roof, the building was thermally uncomfortable for $0.97 \%$ of occupied periods, and $W_{\mathrm{e}}$ exceeded the acceptable limit for seven days. The building passed Criterion 3 as $\Delta$ T never exceeded the upper limit temperature $\left(T_{\text {upp }}\right)$. Figure 9 illustrates the results of simulations for brick walls with an insulated iron sheet roof.

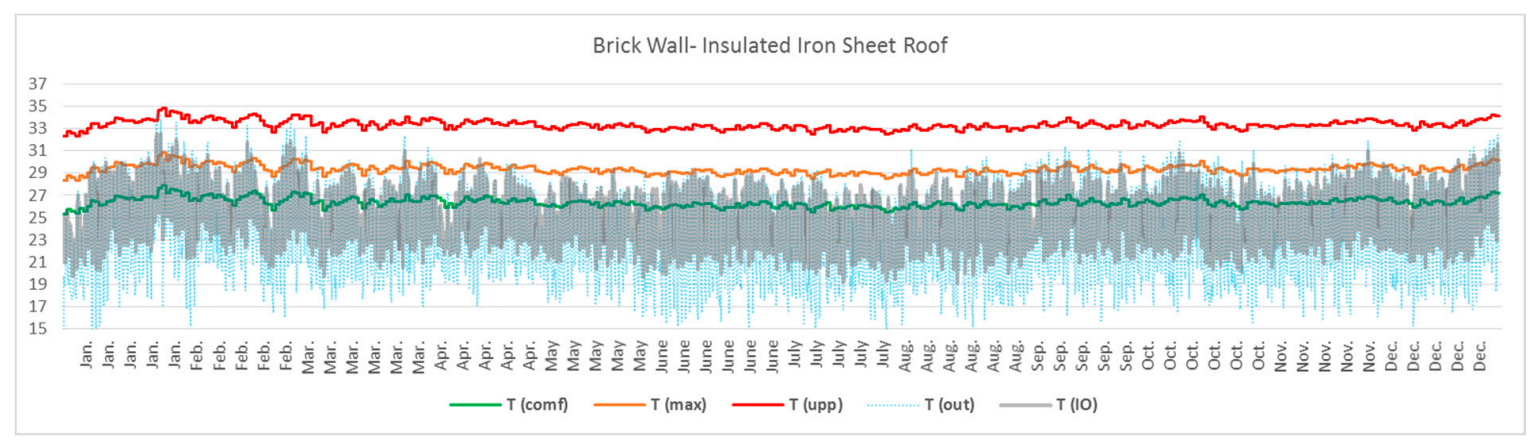

Figure 9. Thermal comfort condition for brick walls with insulated iron sheet roof. 


\subsubsection{Brick Walls and White Painted Iron Sheet Roof}

White iron sheet roof, with low solar absorptance of 0.2 , achieved a considerably good performance in terms of thermal comfort compared to other refurbishment strategies. According to the results, the thermal performance of the painted iron sheet roof was significantly better than the base case with an ordinary iron sheet roof. However, similar to other refurbishment methods, white iron sheet roof failed Criterion 2 of TM52 comfort criteria. The results indicate that the building was thermally uncomfortable only for $1.11 \%$ of occupied periods, and $\mathrm{W}_{\mathrm{e}}$ exceeded the acceptable limit for six days. Moreover, similar to other refurbishment strategies, $\Delta \mathrm{T}$ never exceeded the $4{ }^{\circ} \mathrm{C}$ limit. Figure 10 shows the results of simulations for brick walls with painted iron sheet roof.

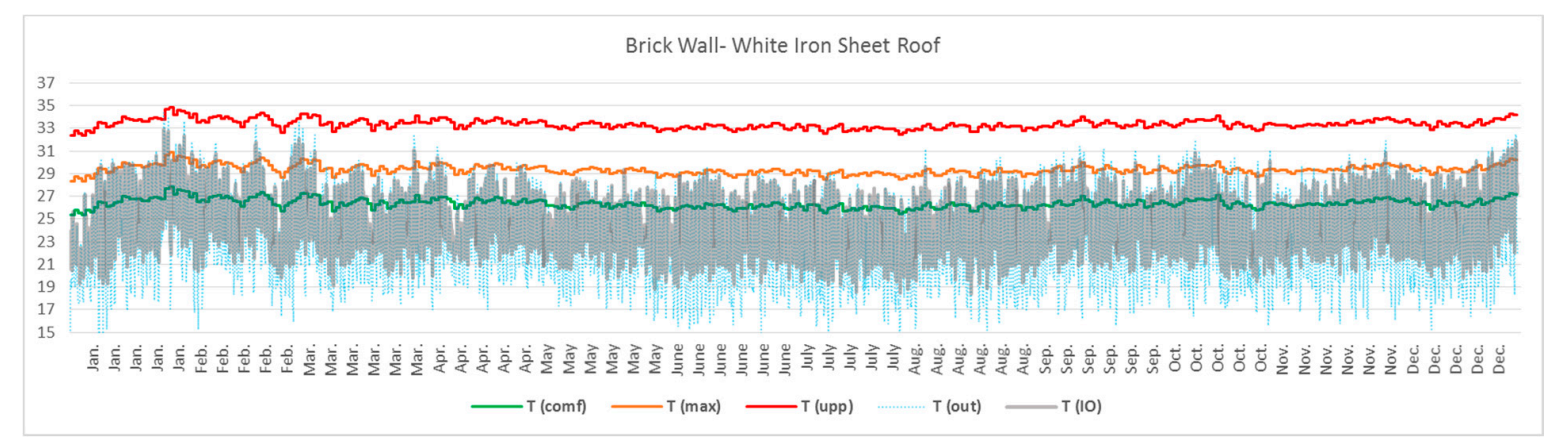

Figure 10. Thermal comfort condition for brick walls with painted iron sheet roof.

\subsubsection{Brick Walls and Double-Skin Iron Sheet Roof}

An additional layer of iron sheet above the existing roof (double-skin iron sheet roofing) achieved similar performance to the false plasterboard ceiling, explained above. For the double-skin roof, the building was found to be for $2.37 \%$ of occupied periods uncomfortable (Criterion 1 ). $\mathrm{W}_{\mathrm{e}}$ was also above the acceptable limit for nine days (Criterion 2). As for Criterion 3, $\Delta \mathrm{T}$ did not exceed the limiting temperature. Overall, similar to all other refurbishment strategies, double skin roofing passed the thermal comfort requirements, as it failed in only one Criterion out of three. Figure 11 illustrates the thermal comfort conditions for a double-skin iron sheet roof.

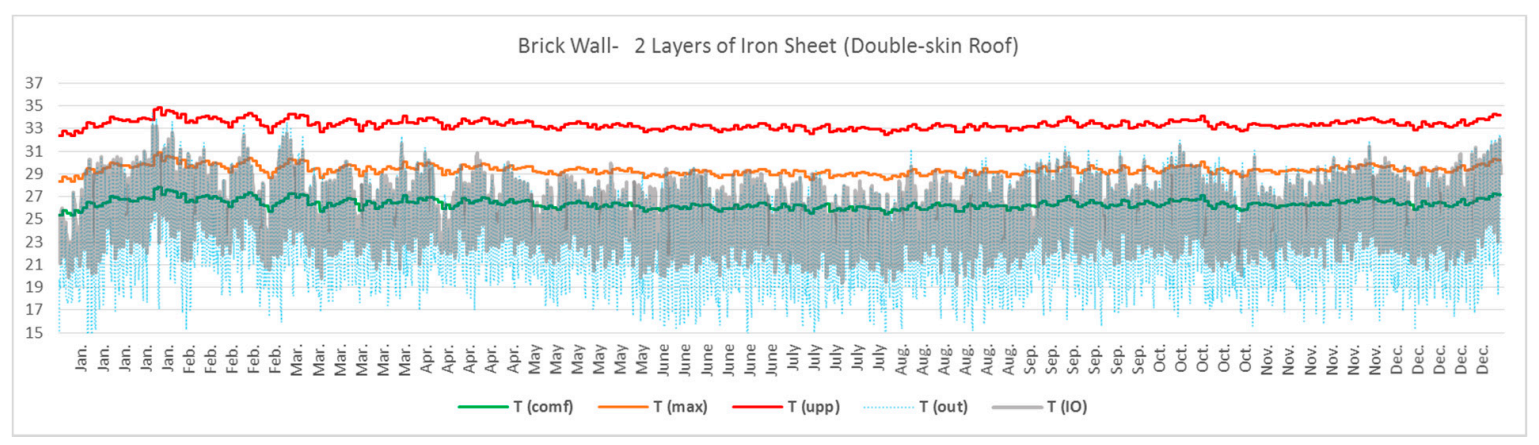

Figure 11. Thermal comfort condition for double-skin iron sheet roof.

\section{Discussion}

According to the results of this study, average indoor operative temperatures of $26{ }^{\circ} \mathrm{C}$ and $29^{\circ} \mathrm{C}$ are, respectively, the ideal comfortable and maximum acceptable indoor temperature in naturally ventilated buildings in Kampala. However, a maximum indoor temperature of up to $31{ }^{\circ} \mathrm{C}$ was also found to be acceptable in hotter months of the year. It should be noted that the comfortable temperature does not fluctuate dramatically throughout the year thanks to the consistent tropical 
weather conditions in Kampala. Therefore, arguably, an average indoor operative temperature of $26^{\circ} \mathrm{C}$ can be used as the comfortable temperature for thermal comfort evaluations in Kampala.

Table 5 summarises the results of the simulations in Section A where the current conditions were studied. According to the results, only four out of 10 construction methods passed TM52 thermal comfort criteria. Iron sheet roofing failed the requirements regardless of walling method. The results reveal that the most critical factor affecting occupants' thermal comfort in low-rise naturally ventilated low-income homes in Kampala is the roof construction method/material.

Table 5. Summary of thermal comfort conditions for prevailing construction methods/materials.

\begin{tabular}{|c|c|c|c|c|}
\hline TM52 Criteria & \multirow{2}{*}{ Criterion $1 *$} & \multirow{2}{*}{ Criterion $2 *$} & \multirow{2}{*}{ Criterion $3 *$} & \multirow{2}{*}{ Overall Pass/Fail } \\
\hline Construction Method & & & & \\
\hline Adobe \& Iron Sheet Roof & $8.41 \%$ & 65 & 6 & Fail \\
\hline Adobe \& Thatched Roof & $0.57 \%$ & 3 & 0 & Pass \\
\hline Brick \& Iron Sheet Roof & $7.96 \%$ & 56 & 2 & Fail \\
\hline Brick \& Thatched Roof & $0.84 \%$ & 5 & 0 & Pass \\
\hline Hollow Concrete Blocks \& Iron Sheet Roof & $13.69 \%$ & 148 & 39 & Fail \\
\hline Hollow Concrete Blocks \& Thatched Roof & $3.24 \%$ & 15 & 0 & Fail \\
\hline Solid Concrete Blocks \& Iron Sheet Roof & $7.02 \%$ & 45 & 2 & Fail \\
\hline Solid Concrete Blocks \& Thatched Roof & $0.75 \%$ & 5 & 0 & Pass \\
\hline Stabilised Soil Blocks \& Iron Sheet Roof & $7.51 \%$ & 49 & 2 & Fail \\
\hline Stabilised Soil Blocks \& Thatched Roof & $0.83 \%$ & 5 & 0 & Pass \\
\hline
\end{tabular}

* Refer to Table 4 for more information.

Figure 12 shows the sun path diagram in Kampala. According to the figure, the sun falls on south facing walls during December and on north facing walls during June. Higher solar transmittance is therefore expected during the hottest periods of the year from south facing windows. Table 6 confirms this finding. According to Table 6, transmitted solar radiation through the window in January and December is over $100 \%$ more than the periods between March and September. However, due to the relatively small size of the window in this study, transmitted solar radiation through the window is not a major issue. Solar transmittance could, however, become a major issue for large windows/openings in Kampala.

Table 6. Monthly average transmitted solar radiation rate through the window (W).

\begin{tabular}{cc}
\hline Month & Transmitted Solar Radiation \\
\hline January & 93.2 \\
February & 69.5 \\
March & 44.3 \\
April & 41.2 \\
May & 40.1 \\
June & 39.4 \\
July & 40.4 \\
August & 41.3 \\
September & 41.8 \\
October & 56.2 \\
November & 78.8 \\
December & 98.3 \\
\hline
\end{tabular}

Moreover, according to Figure 12, the sun has a very high altitude during the entire year, which indicates considerably higher solar heat gain through the roof compared to other building elements. This is supported by Figure 13, which shows the average monthly and annual solar radiation rates per area for the walls and roofs. 


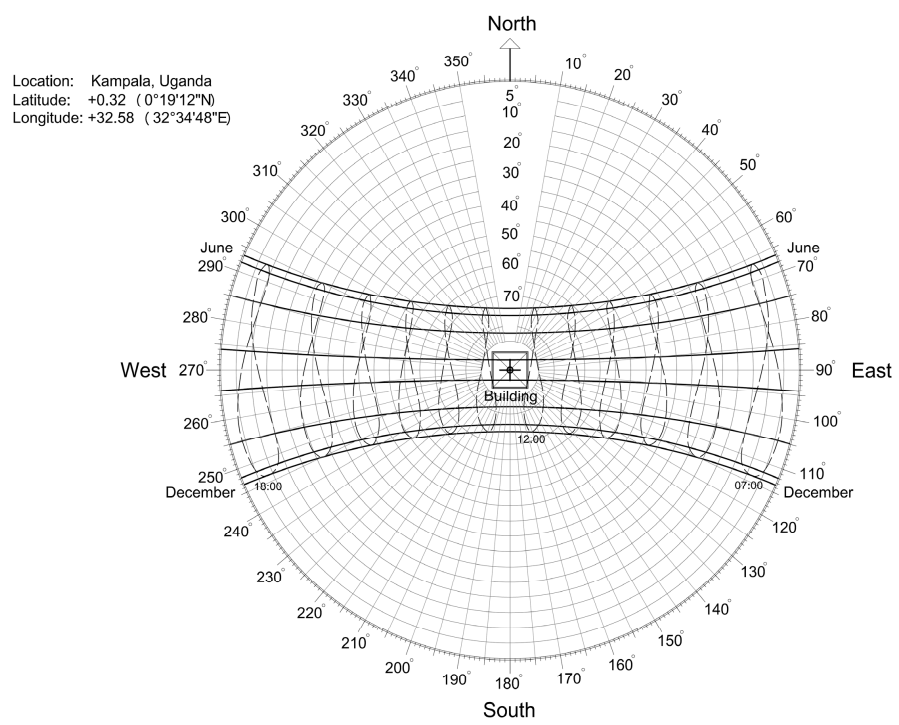

Figure 12. Sun path diagram for Kampala.

According to Figure 13, the average annual heat gain of the roof is over 2.6 times higher than other elements of the buildings. The average monthly heat gain from the roof has, in some cases (e.g., during February), been over four times more than from the walls. This supports the findings of Section A, which highlighted the roof as the key element affecting thermal comfort in Kampala.

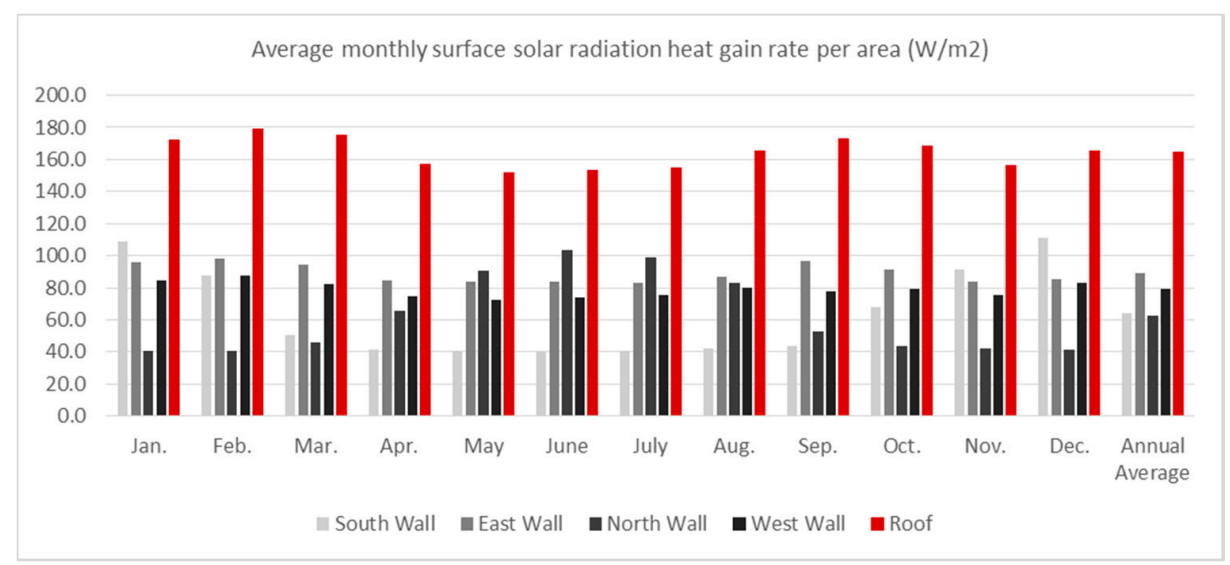

Figure 13. Average monthly and annual surface solar radiation heat gain rate per area $\left(\mathrm{W} / \mathrm{m}^{2}\right)$.

Table 7 summarises the results of simulations for the refurbishment strategies in comparison to the base case (brick wall-iron sheet roof). According to the results, considering any of the refurbishment strategies would significantly improve thermal comfort conditions. In fact, all refurbishment strategies passed TM52 thermal comfort criteria; however, some performed better than others. The results reveal that the insulated roof is the most effective method that can be considered to improve thermal comfort conditions in low-income houses. The results also reveal that insulated roof, insulated ceiling and painted roof had almost identical performance. However, it should be noted that painted roofs may require regular maintenance to keep them clean and free of dirt. This is because built-up dirt will considerably increase absorptivity [17] and deteriorate the performance of the roof. According to the results, although there have been significant improvements of over $560 \%$, reducing the risk of overheating compared to the base case (for Criterion 2), all refurbishment strategies failed Criterion 2, which indicates the severity of overheating within a day as a function of temperature rise and its duration [21]. Although this could be a concern in the context of low-income housing in 
Uganda, considering significant improvements and given the fact that Criterion 3 (as the indication of extreme overheating beyond which "normal adaptive actions will be insufficient to restore personal comfort" [21]) has been met in all cases, such concerns are arguably negligible. Moreover, according to CIBSE TM52, Criterion 3 could also be considered as an indicator of "hot weather conditions and future climate scenarios". Therefore, all refurbishment strategies would help low-income populations become more climate resilient with respect to global warming during the next 70 years.

Table 7. Summary of thermal comfort conditions for refurbishment strategies.

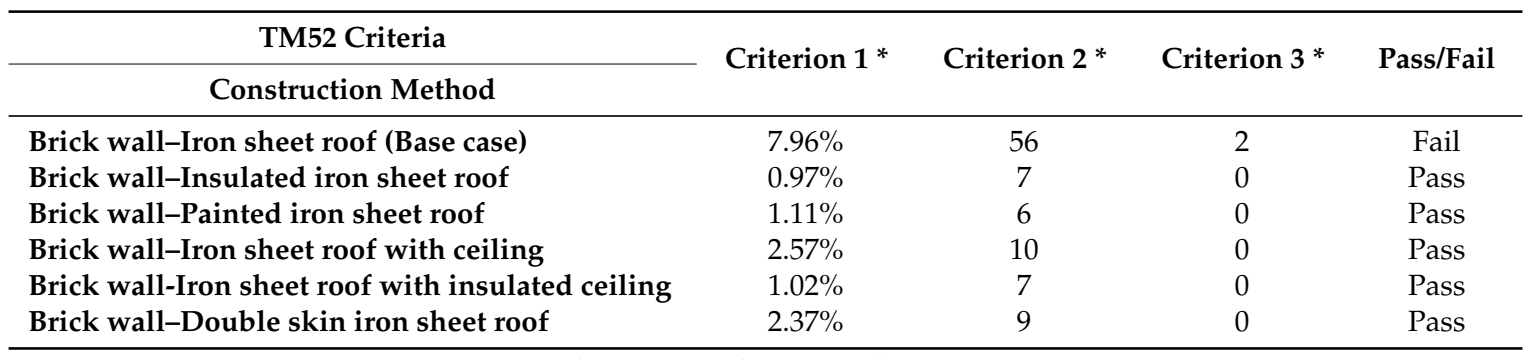

* Refer to Table 4 for more information.

A sensitivity analysis was carried out to investigate the effects of various thermal insulation thickness on the performance of the roof and ceiling. Table 8 shows the results of simulations for two additional thicknesses of $15 \mathrm{~mm}$ and $25 \mathrm{~mm}$. According to the results, reducing insulation thickness to $15 \mathrm{~mm}$ deteriorated the conditions for Criterion 1, increasing the risk of thermal discomfort (frequency of overheating) by around $78 \%$ and $54 \%$ for insulated roof and insulated ceiling, respectively; however, Criterion 1 remained below the acceptable level of $3 \%$. The reduced thickness, however, did not greatly affect Criterion 2 and Criterion 3, and all tested scenarios passed thermal comfort requirements (Table 8). A thinner thermal insulation could therefore be considered to reduce the costs of refurbishment for low-income populations.

Table 8. Sensitivity analysis for two additional thermal insulation thicknesses.

\begin{tabular}{|c|c|c|c|c|}
\hline TM52 Criteria & \multirow{2}{*}{ Criterion $1 *$} & \multirow{2}{*}{ Criterion $2 *$} & \multirow{2}{*}{ Criterion $3 *$} & \multirow[t]{2}{*}{ Pass/Fai } \\
\hline Construction Method & & & & \\
\hline Insulated iron sheet roof $50 \mathrm{~mm}$ & $0.97 \%$ & 7 & 0 & Pass \\
\hline Insulated iron sheet roof $25 \mathrm{~mm}$ & $1.18 \%$ & 7 & 0 & Pass \\
\hline Insulated iron sheet roof $15 \mathrm{~mm}$ & $1.73 \%$ & 8 & 0 & Pass \\
\hline Iron sheet roof with insulated ceiling $50 \mathrm{~mm}$ & $1.02 \%$ & 7 & 0 & Pass \\
\hline Iron sheet roof with insulated ceiling $25 \mathrm{~mm}$ & $1.24 \%$ & 8 & 0 & Pass \\
\hline Iron sheet roof with insulated ceiling $15 \mathrm{~mm}$ & $1.57 \%$ & 7 & 0 & Pass \\
\hline
\end{tabular}

* Refer to Table 4 for more information.

Double skin roofing and false ceilings also significantly improved the thermal comfort conditions. Although less effective than paints with low solar absorptance, it could be argued that inclusion of false ceiling and/or double-skin roofing would probably be more practical in the long-term, as these options require less maintenance compared to painted roofs. Indeed, one of the major reasons for moving away from thatched roofs in Uganda is their high maintenance requirements compared to iron sheet roofs. Moreover, although insulated ceilings and roofs improved thermal comfort conditions, considering affordability issues and limited access of low-income populations to such materials, insulation should be considered as the next priority and only if financially viable. Obviously, a combination of the above refurbishment strategies would further improve thermal comfort conditions, although the feasibility of such strategies for low-income people with a daily income of $\$ 1.25[3]$ is open to serious questions.

\section{Conclusions}

This paper evaluated the effects of various construction methods on thermal comfort in low-income houses in Uganda. Dynamic thermal simulations (DTS) were conducted with EnergyPlus 
to evaluate the risk and extent of overheating in single storey naturally ventilated houses. According to the results, roofing methods/materials greatly affected thermal comfort conditions in the studied buildings. The risk of overheating and thermal discomfort in buildings with iron sheet roofs was up to 15 times higher than in buildings with thatched roofs. Walling methods/materials were found to be less critical compared to the roofs; however, some materials such as hollow-concrete blocks significantly deteriorated thermal comfort conditions. Overall, low thermal conductivity and solar absorptance of roofs followed by a high thermal mass of walls were found to be the key factors in reducing the risks of overheating and thermal discomfort in low-income free-running houses in the tropical climate of Kampala.

Refurbishment strategies were also investigated using DTS. All refurbishment strategies considerably improved the conditions; however, insulated roofs and ceilings followed by painted roofs were found to be the most effective methods. Nevertheless, considering the close performance of all refurbishment strategies in addition to practicality (e.g., maintenance requirements), affordability and availability issues surrounding some of the investigated materials, particularly for low-income people, the prioritised refurbishment strategies are recommended as follows:

1. Inclusion of false ceiling

2. Double-skin roofing

3. White painting roofs with low-solar absorptance

4. Insulated roof (warm roof)

5. Insulated ceiling (cold roof)

It should be noted that all refurbishment strategies helped to pass Criterion 3 of CIBSE TM52, as an indicator of "future climate scenarios", making low-income houses/populations more climate resilient in respect of global warming during the next 70 years.

This paper intended to evaluate the current conditions and develop simple, effective and practical refurbishment strategies to improve thermal comfort conditions for low-income populations in Uganda. Further research is required to evaluate the actual performance of construction methods and materials as well as the suggested refurbishment strategies using physical measurements on site. More research is also required to evaluate the effects of future climate scenarios and other parameters such as shadings, occupancy patterns/behaviours and ventilation rates and strategies on thermal comfort in low-income houses in Uganda. The cost implicatons of the abovementioned refurbishment strategies should also be investigated.

Acknowledgments: This document is an output from a research project "Energy and Low-Income Tropical Housing" co-funded by UK aid from the UK Department for International Development (DFID), the Engineering and Physical Science Research Council (EPSRC) and the Department for Energy and Climate Change (DECC), for the benefit of developing countries. The views expressed are not necessarily those of DFID, EPSRC or DECC.

Conflicts of Interest: The author declares no conflict of interest.

\section{Abbreviations}

Operative temperature $\left(\mathrm{T}_{\mathrm{OP}}\right)$ : "the operative temperature combines the air temperature and the mean radiant temperature into a single value to express their joint effect". The operative temperature can be calculated from the following equation when the indoor air speeds is below $0.1 \mathrm{~m} / \mathrm{s}$ [21]:

$T_{\text {op }}=\frac{1}{2} T_{i}+\frac{1}{2} T_{r}$, where $T_{i}$ is the indoor air temperature $\left({ }^{\circ} \mathrm{C}\right)$ and $T_{r}$ is the mean radiant temperature $\left({ }^{\circ} \mathrm{C}\right)$.

Comfortable temperature $\left(\mathrm{T}_{\text {comf }}\right)$ : the acceptable range of operative temperatures as a function of weighted running mean of the daily mean outdoor air temperature $\left(\mathrm{T}_{\mathrm{rm}}\right)$. Comfortable temperature can be calculated from the following equation:

$T_{\text {comf }}=0.33 T_{r m}+18.8$, where $T_{r m}$ is $=(1-\alpha)\left(T_{d}-1+\alpha T_{d}-2+\alpha 2 T_{d}-3 \ldots\right)$ and $\alpha$ is a constant $(\alpha<1)$ and $\mathrm{T}_{\mathrm{d}}-1, \mathrm{~T}_{\mathrm{d}}-2 \ldots$ are the daily mean temperatures for the previous days [21].

Maximum temperature $\left(\mathrm{T}_{\max }\right)$ : is the maximum acceptable operative temperature in free-running buildings. $\mathrm{T}_{\max }$ can be calculated from the following equation: $\mathrm{T}_{\max }=0.33 \mathrm{~T}_{\mathrm{rm}}+21.8$ [20]. In other words, $\mathrm{T}_{\max }=\mathrm{T}_{\text {comf }}+3$

Daily weighted exceedance $\left(\mathbf{W}_{\mathbf{e}}\right)$ : shows the severity of overheating in any single day in degree hours based on Annex F, "Method B Degree hours criteria" of BS EN 15251 [20]. $W_{\mathrm{e}}$ is the number of occupied hours during which the operative temperature exceeds the acceptable range multiplied by a factor that is a function of exceeded degrees over the acceptable range [21] 


\section{References}

1. Byakola, T. Improving Energy Resilience in Uganda. Helio International, 2007. Available online: http:/ /www.helio-international.org/Uganda.En.pdf (accessed on 7 April 2016).

2. United Nations Department of Economic and Social Affairs (UNDESA). World Urbanization Prospects, The 2014 Revision; UNDESA: New York, NY, USA, 2014.

3. United Nations Development Programme (UNDP). Human Development Report 2015, Work for Human Development; UNDP: New York, NY, USA, 2015.

4. Malik, K. Human Development Report 2014, Sustaining Human Progress: Reducing Vulnerabilities and Building Resilience; United Nations Development Programme: New York, NY, USA, 2014.

5. Economic Policy Research Centre (EPRC). Uganda 2013 FinScope 9 Survey Report Findings, Unlocking Barriers to Financial Inclusion; EPRC: Kampala, Uganda, 2013.

6. National Planning Authority (NPA). National Development Plan (2010/11-2014/15); NPA: Kampala, Uganda, 2010.

7. Uganda Bureau of Statistics (UBOS). Uganda Demographic and Health Survey 2011; UBOS: Kampala, Uganda, 2012.

8. United Nations Human Settlements Programme (UN-HABITAT). Country Programme Document 2008-2009, UGANDA, United Nations Human Settlements Programme (UN-HABITAT), HS Number: HS/1112/09E; United Nations Human Settlements Programme: Nairobi, Kenya, 2009.

9. Engineering Ministries International-East Africa (EMI). Architectural Design Guide; EMI: Kampala, Uganda, 2012.

10. ACTwatch Group \& PACE/Uganda. Household Survey, Uganda, 2012 Survey Report; Population Services International: Washington, DC, USA, 2013.

11. Uganda Bureau of Statistics (UBOS). 2002 Uganda Population and Housing Census, Analytical Report; UBOS: Kampala, Uganda, 2006.

12. Hashemi, A.; Cruickshank, H.; Cheshmehzangi, A. Environmental Impacts and Embodied Energy of Construction Methods and Materials in Low-Income Tropical Housing. Sustainability 2015, 7, 7866-7883. [CrossRef]

13. Hashemi, A.; Cruickshank, H. Delivering Sustainable Low-income Housing in Uganda, Challenges and Opportunities. OIDA Int. J. Sustain. Dev. 2015, 8, 47-60.

14. Watkins, K. Human Development Report 2007/2008, Fighting Climate Change: Human Solidarity in a Divided World; United Nations Development Programme (UNDP); Palgrave Macmillan: New York, NY, USA, 2007.

15. Hashemi, A.; Cruickshank, H.; Cheshmehzangi, A. Improving Thermal Comfort in Low-income Tropical Housing: The Case of Uganda. In Proceedings of the ZEMCH 2015 International Conference, Lecce, Italy, 22-25 September 2015.

16. Uganda Bureau of Statistics (UBOS). Uganda National Household Survey 2009/10; UBOS: Kampala, Uganda, 2010.

17. Chartered Institution of Building Services Engineers (CIBSE). Guide A: Environmental Design; CIBSE: London, UK, 2015.

18. Perez, A. Interlocking Stabilised Soil Blocks, Appropriate Earth Technologies in Uganda, HS/1184/09E; United Nations Human Settlements Programme: Nairobi, Kenya, 2009.

19. Olweny, M.R.O. Designing a Satisfactory Indoor Environment with Particular Reference to Kampala, Uganda. Master's Dissertation, The University of Adelaide, Adelaide, Australia, 1996.

20. British Standards Institution (BSI). BS EN 15251: 2007: Indoor Environmental Input Parameters for Design and Assessment of Energy Performance of Buildings Addressing Indoor Air Quality, Thermal Environment, Lighting and Acoustics; BSI: London, UK, 2007.

21. Chartered Institution of Building Services Engineers (CIBSE). CIBSE TM52: 2013: The Limits of Thermal Comfort: Avoiding Overheating in European Buildings; CIBSE: London, UK, 2013.

(C) 2016 by the author; licensee MDPI, Basel, Switzerland. This article is an open access article distributed under the terms and conditions of the Creative Commons Attribution (CC-BY) license (http://creativecommons.org/licenses/by/4.0/). 